\title{
Twin-fluid atomization of viscous liquids: The effect of atomizer construction on breakup process, spray stability and droplet size
}

MLKVIK, M.; STÄHLE, P.; SCHUCHMANN, H.; GAUKEL, V.; JEDELSKÝ, J.; JÍCHA, M.

International Journal of Multiphase Flow

2015, vol. 77, December 2015, pp. 19-31

ISSN: 0301-9322

DOl: https://doi.org/10.1016/j.jimultiphaseflow.2015.06.010

Accepted manuscript

(C) 2012. This manuscript version is made available under the CC-BY-NC-ND 4.0 license (http://creativecommons.org/licenses/by-nc-nd/4.0/), doi:

https://doi.org/10.1016/j.ijmultiphaseflow.2015.06.010

Final version available from https://www.sciencedirect.com/science/article/pii/s0301932215001494 
Title: TWIN-FLUID ATOMIZATION OF VISCOUS LIQUIDS: THE EFFECT OF ATOMIZER CONSTRUCTION ON BREAKUP PROCESS, SPRAY STABILITY AND DROPLET SIZE

Corresponding Author: Marek Mlkvik, mlkvik@fme.vutbr.cz, +421 907304850

Authors:

M. Mlkvik, Brno University of Technology, Technicka 2896/2, 61669 Brno, Czech Republic

P. Stähle, Karlsruhe Institute of Technology, Institute of Process Engineering in Life Sciences, Section I: Food Process Engineering, Kaiserstraße 12, 76131 Karlsruhe, Germany, philipp staehle@kit edu

H. P. Schuchmann, Karlsruhe Institute of Technology, Institute of Process Engineering in Life Sciences, Section I: Food Process Engineering, Kaiserstraße 12, 76131 Karlsruhe, Germany, heike schuchmann@kit edu

V. Gaukel, Karlsruhe Institute of Technology, Institute of Process Engineering in Life Sciences, Section I: Food Process Engineering, Kaiserstraße 12, 76131 Karlsruhe, Germany, volkergaukel@kit edu

J. Jedelsky, Brno University of Technology, Technicka 2896/2, 61669 Brno, Czech Republic, jedelsky@fme.vutbr.cz

M. Jicha, Brno University of Technology, Technicka 2896/2, 61669 Brno, Czech Republic, jicha@fme.vutbr.cz

Keywords: twin-fluid atomizer, two-phase flow, atomization, liquid breakup, spray imagining, spray stability, comparison of atomizers

HIGHLIGHTS

- We compare a Y-jet, effervescent and an in-house developed CFT atomizer for spraying viscous liquids. 
- The comparison looked at spray stability, primary breakup visualization and droplet size.

- The best stability was observed with the Y-jet atomizer and the "outside in liquid" atomizer.

- $\quad$ The breakup for all liquids with the OIG, OIL and CFT atomizers was characterized by $\mathrm{We}=1-10$. This was considerably lower with the $\mathrm{Y}$-jet atomizer $(\mathrm{We}=0.1-3)$.

- The smallest droplets were produced by the OIL atomizer.

\section{ABSTRACT}

This study focuses on the low-pressure spraying of viscous liquids ( $\mu=60,147$ and $308 \mathrm{mPa} \cdot \mathrm{s}$ ) using four types of internal-mixing twin-fluid atomizers. We compare two well-known designs, namely the Y-jet and "outside in gas" (OIG) effervescent atomizers, with our new design (CFT) and an "outside in liquid" (OIL) configuration for the effervescent atomizer. The atomizers were operated by two gas inlet pressures $(0.14$ and $0.28 \mathrm{MPa})$ and various gas-to-liquid ratios $(G L R=2.5,5,10$ and 20\%). The comparison focused on internal liquid-gas flow, spray stability, primary breakup, and droplet size.

The primary breakup was investigated using a high-speed camera. A near-nozzle spray pattern was related to the ratio of forces, which affects liquid deformation, by dimensionless numbers. The breakup was driven mainly by air resistance in the OIG, OIL, and CFT atomizers and by surface tension in the $\mathrm{Y}$-jet atomizer.

The OIL and Y-jet atomizers provided the most stable spray, regardless of the working regime or atomized liquid. The OIL atomizer produced the smallest droplets at low GLRs, while the droplet sizes for the Y-jet atomizer increased significantly at low GLRs. For the OIG atomizer, spray stability was influenced by the GLR, with the best stability being achieved at a GLR of $10 \%$ and $20 \%$. The presence of large droplets at a low GLR caused an increase in droplet size. Switching the inlet ports of the effervescent atomizer (OIG-OIL) affected the internal flow, which differed under the same working regimes for these two configurations. The 
internal flow pattern of the OIL atomizer was estimated to be annular for all regimes, while for the OIG atomizer, it changed from a plug to slug flow with an increase in the GLR.

\section{INTRODUCTION}

Internal-mixing twin-fluid atomizers have been used in countless commercial applications over the recent decades, such as in gas turbine engines (Lefebvre 1988), internal combustion engines (Wade 1999), scramjet engines (Gadgil 2011), spray drying (Mujumdar 2010), spray coating (Esfarjani 2009, Qian 2011), process industries (Loebker 1997) and fire suppression (Huang 2011, Lal 2010). Y-jet nozzles in particular have been widely used in oil boilers, industrial furnaces, agricultural sprays, spray dryers and paint sprays (Zhou, 2010).

Atomizers with internal mixing are favored for their good atomization quality at low pressure (Sovani 2001) and their low sensitivity to a liquid's rheological properties when compared with high-pressure atomizers. Twin-fluid atomizers provide easy and independent control of the individual spray parameters (Karnawat 2006). The consumption of atomizing gas is lower than with their externally mixed counterparts.

The capability to process highly viscous liquids is advantageous in several areas, especially in the combustion of heavy fuels, liquid wastes (Buckner 1990, Ferreira 2009, Jedelsky 2009, Kermes 2008, Loebker 1998), coal-water (Chawla 1985, Daviault 2012, Jagannathan 2011), and coke sludge slurries. It also helps in the spray drying of food (with suspensions of water and gelatinized native corn starch or native waxy corn starch, Schröder et al., 2011 ) and pharmaceutical and consumer products (PEO solutions (Broniarz-Press 2010) such as water-oil emulsions (Broniarz-Press 2009 Schröder et al., 2012), black liquor (Risberg 2009), and liquids for fluid catalytic cracking (Jolodar 2005).

Published designs for internal-mixing twin-fluid atomizers appear in a variety of internal configurations, as indicated above and in several reviews (Jedelsky 2009, Sovani 2001). The internal design of an atomizer certainly affects its performance and predetermines its possible uses. In some applications-such as combustion, surface coating, and powder generation-a temporally unsteady spray has a negative effect. For example, it leads to increased combustion noise and it puts extra load on the combustion chamber. On the other hand, some engineering applications can profit from such an unsteady spray. For example, it can enhance the air 
entrainment rate in consumer products (Liu 2011, Panao 2005). The generation of a fine spray, or the ability to control spray size, is a traditionally common requirement for most applications. The internal flow is a process that greatly influences the work of twin-fluid atomizers (Bukner, 1991, Lorcher 2003, Stähle et al. 2014). This can be estimated using theoretical flow regime maps (Barnea 1987) or experimental ones (Baker 1954, Hewit and Roberts 1969, Golan and Stenning 1969). Theoretical maps have the advantage of not being limited by experimental parameters. Experimental maps, meanwhile, can only be applied with the specific range of experimental parameters (e.g. pipe size, working fluids, GLR) specified by the researcher. This disadvantage was partially solved by Schicht (1969) and Weisman and Kang (1981) when they attempted to find generalized dimensionless parameters to cover a wide range of working parameters. Another approach to identify the internal flow, which is especially useful for $\mathrm{Y}$-jet atomizers, was introduced by Song (1996). He used the liquid-to-gas momentum ratio $\Phi=m r^{2} \cdot d^{2} \cdot \rho_{g} \cdot \sin \Theta /\left(m_{g}^{2} \cdot d_{g}^{2} \cdot \rho_{l}\right)$ and related it to the observed internal flow regime. Here, the mass flux per surface unit is denoted as " $m$ ", density as " $\rho$ ", port diameter as " $d$ " and the intersecting angle as " $\Theta$ ". The indexes "I " and " $g$ " denote the liquid or gas.

A number of studies deal with twin-fluid atomizers (Ochowiak 2013), Xiuyuan 2013, Pougatch 2014, Barroso 2014, Hong 2014), but these are very rarely compared. Chung (2000), Linchetta (2002), Ferreira (2009) or Gottlieb (2004) compare their designs with commercial atomizers, but this does not extend over several types of these devices. In this paper, we therefore decided to provide a systematic comparison of four selected twin-fluid atomizers (Figure 3) that differ widely in their mixing principles under the same working conditions. According to the available literature, each type was evaluated in several variations of its internal dimensions, with the best being chosen for this study. Our aim was to investigate differences in the breakup process, spray stability and droplet size while spraying liquids of different viscosity. We judged their performance and evaluated their potential for various applications. The Y-jet and OIG atomizers are well-known atomizing devices that are widely used in many industrial applications (Mullinger 1974, Lefebvre 1988, Chung 2000, Sovani 2001). The OIL atomizer is a variant of the effervescent atomizer, where the liquid and gas ports are switched, thus influencing the mixing mechanism of the flow components. The CFT atomizer is a new design that was recently developed at the Brno University of Technology. It was inspired by atomizers 
invented by Chin (1995), Ferreira (2001), and Tamaki (2004), and its name represents the initials of these authors.

\section{EXPERIMENT}

The near-nozzle spray was observed using a high-speed camera (OLYMPUS i-speed2) with a framerate of $10000 \mathrm{fps}$ and an exposition time of $5 \mu \mathrm{s}$. The measuring volume was illuminated by a continual LED light with a light diffuser being used to provide a uniform image background (Figure 1). The focusing optics comprised a PENTAX TV lens (50 mm, f1:1.4) with extension rings for a total length of $25 \mathrm{~mm}$ in order to achieve image magnification. Droplet sizes were measured $100 \mathrm{~mm}$ downstream of the discharge orifice using a Malvern Spraytec laser diffraction system.

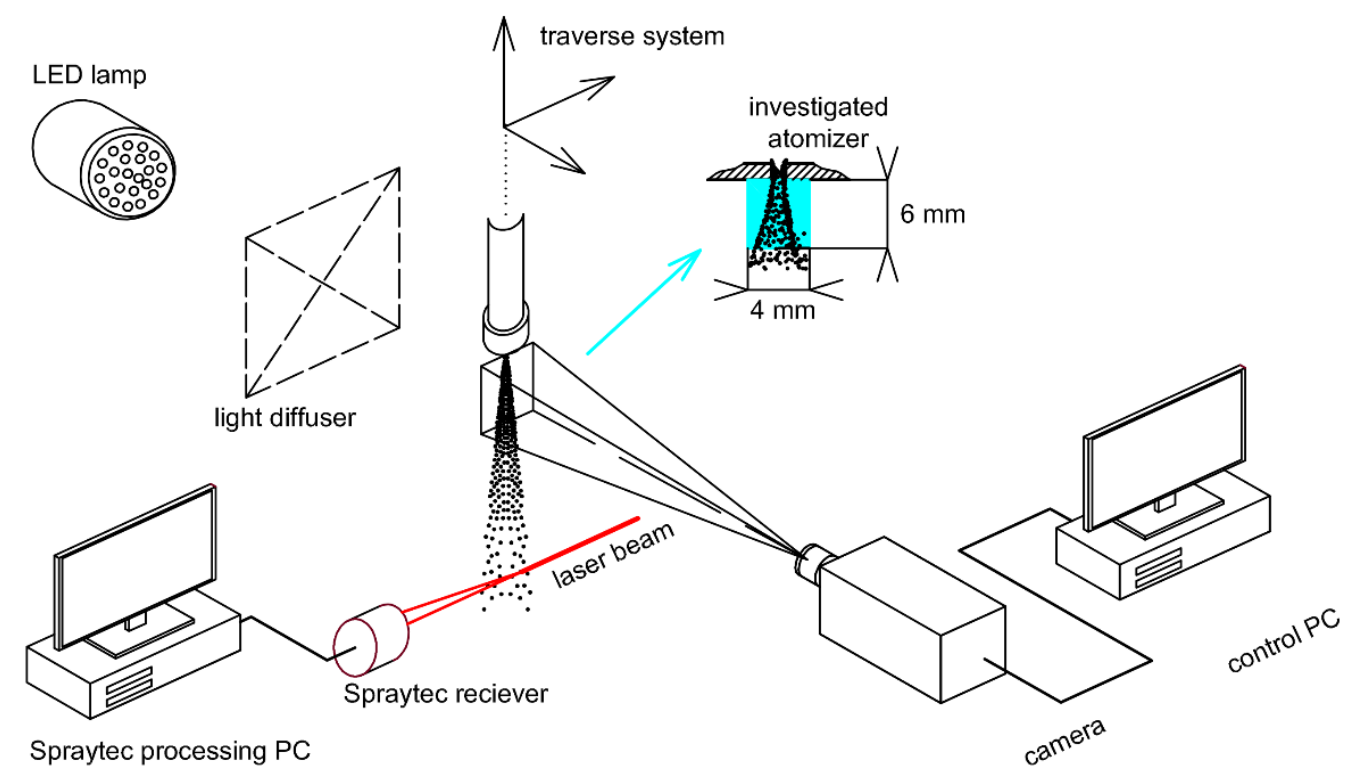

Figure 1. Arrangement of the measurement and visualization systems

The atomizers were operated under a wide range of working parameters defined by the inlet air pressure $(\Delta p=0.14$ and $0.28 \mathrm{MPa})$ and gas-to-liquid ratio of the mass (GLR $=2.5,5,10$ and 20\%). Three liquids of different viscosity were sprayed (Table 1). The temperature of the air and liquid was kept within $18-20^{\circ} \mathrm{C}$. 
Table 1. Physical properties of the water-maltodextrin solutions at room temperature (Stähle 2013)

\begin{tabular}{ccccc}
\hline $\begin{array}{c}\text { Maltodextrin } \\
\text { concentration [\%] }\end{array}$ & designation & $\mu[\mathrm{mPa} \cdot \mathrm{s}]$ & $\sigma[\mathrm{mN} / \mathrm{m}]$ & $\rho\left[\mathrm{kg} / \mathrm{m}^{3}\right]$ \\
\hline 50 & & & \\
\hline 45 & MD50 & $308 \pm 24$ & $75.736 \pm 1.035$ & $1242 \pm 2$ \\
\hline 40 & MD45 & $143 \pm 16$ & $74.258 \pm 0.778$ & $1121 \pm 2$ \\
\hline & MD40 & $60 \pm 4$ & $74.454 \pm 0.386$ & $1185 \pm 1$
\end{tabular}

${ }^{*} \mu-$ viscosity, $\sigma-$ surface tension, $\rho$ - density

The air inlet pressure was kept constant for varying GLRs. The liquid injection pressure was changed as GLR changed to compensate for the pressure loss between the liquid inlet port and the mixing chamber of the atomizer. This value was measured for safety reasons, namely for the load on the hydraulic system, but it was not recorded.

\subsection{EXPERIMENTAL RIG}

A simplified schematic of the test rig is shown in Figure 2. An eccentric screw pump (2NL 20A, Erich Netzsch GmbH \& CO. Holding KG, Selb, Germany) was used at a constant rotation speed to pump the solutions. The flow was controlled by a bypass valve. The volume flow rate towards the atomizer was adjusted using a needle valve and measured with a flow meter (VSE GmbH, Neuenrande, Germany). Compressed air from a house supply was used and adjusted by a pressure-reducing valve to provide the atomizer with atomization gas. The gas pressure was measured using a pressure gauge just a short distance upstream of the atomizer. A thermal gas mass flow controller (a High-Tech EL-Flow from Bronkhorst Mättig GmbH, Kamen, Germany) indicated the gas mass flow. After ejection, the spray was collected in a vessel that was connected to an exhaust fan. 


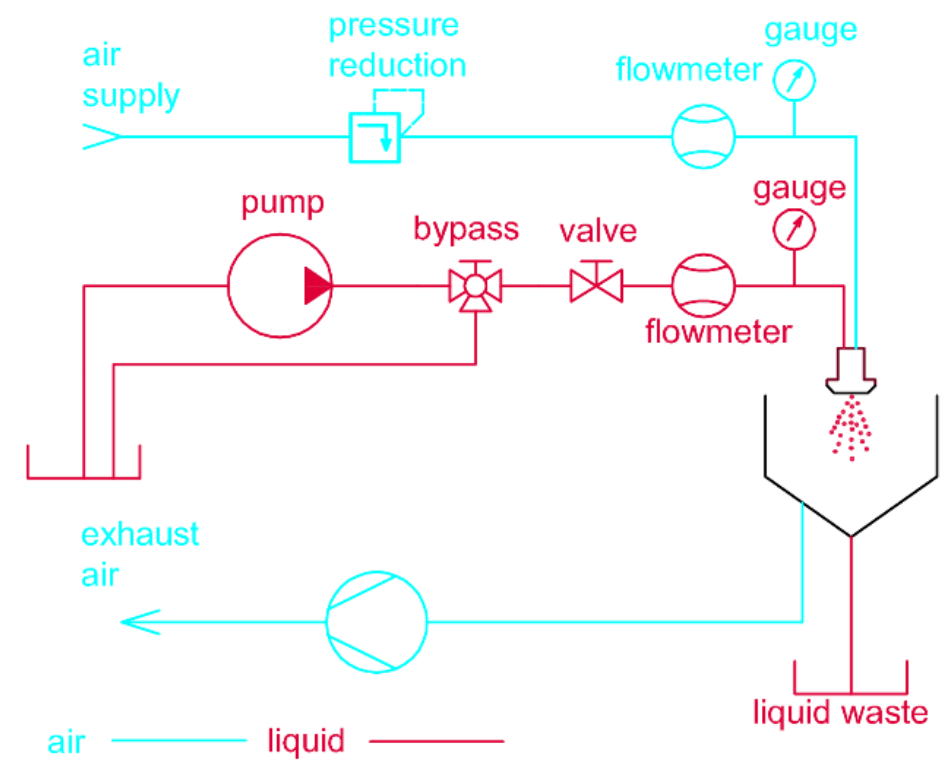

Figure 2. Simplified schematic of the experimental rig

\subsection{ATOMIZERS}

The atomizers investigated are outlined in Figure 3, and their important characteristics are given in Table 2.

The Y-jet atomizer (Figure 3a) is a well-known atomizing device with a simple design (Mullinger 1974) that uses a well-described internal two-phase flow (Song 1996). The internal flow is created by injecting liquid into the high-velocity axial gas stream.

The OIG atomizer (Figure 3b) is frequently reported as well (Lefebvre 1988, Sovani 2001). A two-phase flow is created by introducing gas into the liquid upstream of the discharge orifice through a perforated aerator. The internal two-phase flow pattern for this type of atomizer is mainly affected by the $\Delta p$ and the flow rates of the liquid and gas (Brennen 2005).

The OIL atomizer (Figure 3c) uses a similar design to the OIG atomizer, but the inlet ports are switched. In this case, the air is introduced into the mixing chamber from the top, while the liquid is injected through the perforated wall of the mixing chamber (the aerator in the OIG atomizer). The main difference between these configurations is the mixing mechanism of the flow components, which in this case is more similar to the $\mathrm{Y}$-jet atomizer. 
Inside the CFT atomizer (Figure 3d), gas is introduced from the top of the mixing chamber through four gas ports. The gas ports are tangential to the axis of the atomizer, creating a vortex flow inside the mixing chamber. Liquid is introduced through four ports perpendicular to the main axis of the atomizer.

The atomizers were designed to work with similar gas and liquid flowrates (Table 3). To achieve this, the Y-jet atomizer needed a different diameter for its discharge orifice (Table 2).

a)

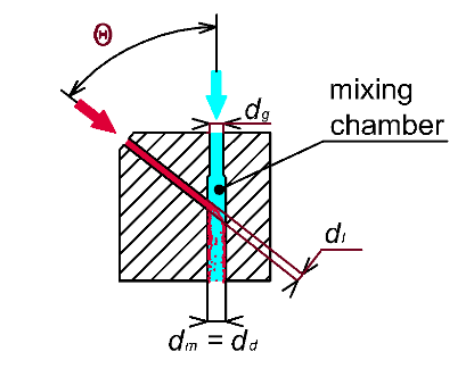

$\checkmark$ Gas

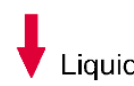

b)

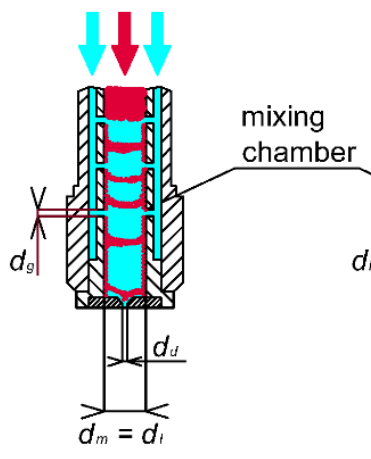

c)

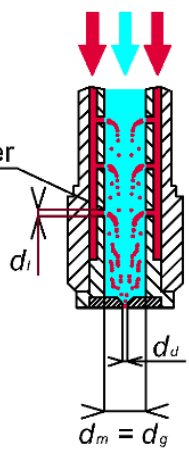

d)

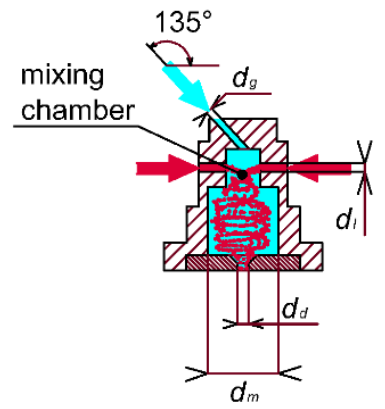

* the drawigns are not figured by the same scale

Figure 3. Schematics of the investigated atomizers: a) Y-jet, b) OIG, c) OIL, d) CFT

Table 2. The important geometrical parameters of the atomizers

\begin{tabular}{lllllll}
\hline & $d_{l}[\mathrm{~mm}]$ & $d_{m}[\mathrm{~mm}]$ & $d_{g}[\mathrm{~mm}]$ & $\Theta$ & $N$ & $d_{d}[\mathrm{~mm}]$ \\
\hline Y-jet & 0.4 & 1 & 0.7 & 52 & 1 & 1 \\
\hline OIG & 9 & 9 & 1 & 90 & 1 & 0.7 \\
\hline OIL & 1 & 9 & 9 & 90 & 20 & 0.7 \\
\hline CFT & 1 & 9 & 1 & 90 & 4 & 0.7 \\
\hline
\end{tabular}

${ }^{*} d_{l}-$ liquid port diameter, $d_{m}-$ mixing chamber diameter, $d_{g}-$ gas port diameter, $\Theta$ - liquid

injection angle, $N$ - number of liquid injectors, $d_{d}$ - discharge orifice diameter

'Table 3. Measured liquid mass flow rates in $[\mathrm{kg} / \mathrm{hod}]$ for all atomizers and working regimes 


\begin{tabular}{|c|c|c|c|c|c|c|c|c|c|c|c|c|c|c|}
\hline & & & \multicolumn{3}{|c|}{$Y$-jet } & \multicolumn{3}{|c|}{ OIG } & \multicolumn{3}{|c|}{ OIL } & \multicolumn{3}{|c|}{ CFT } \\
\hline & & & \multicolumn{3}{|c|}{$\mu[\mathrm{mPa} \cdot \mathrm{s}]$} & \multicolumn{3}{|c|}{$\mu[\mathrm{mPa} \cdot \mathrm{s}]$} & \multicolumn{3}{|c|}{$\mu[\mathrm{mPa} \cdot \mathrm{s}]$} & \multicolumn{3}{|c|}{$\mu[\mathrm{mPa} \cdot \mathrm{s}]$} \\
\hline & & & 60 & 147 & 308 & 60 & 147 & 308 & 60 & 147 & 308 & 60 & 147 & 308 \\
\hline \multirow{4}{*}{\begin{tabular}{l}
$\tilde{\sigma}$ \\
$\stackrel{2}{Z}$ \\
\multirow{J}{J}{} \\
0
\end{tabular}} & $\sigma$ & 2.5 & 3.91 & 3.36 & N1 & 3.56 & N1 & N1 & 3.91 & 2.91 & N1 & 3.44 & N1 & N2 \\
\hline & d & 5 & 3.56 & 3.14 & N1 & 3.50 & 2.13 & N1 & 3.79 & 3.03 & $\mathrm{~N} 1$ & 3.32 & 2.91 & N2 \\
\hline & $\frac{r}{4}$ & 10 & 2.61 & 2.47 & 0.99 & 2.37 & 2.13 & 1.80 & 2.73 & 2.02 & 3.23 & 3.3 & 2.13 & $\mathrm{~N} 2$ \\
\hline & & 20 & 1.24 & 1.23 & N3 & 1.30 & 1.46 & 0.93 & 1.42 & 0.90 & 2.11 & 1.78 & 1.12 & N2 \\
\hline \multirow{4}{*}{ 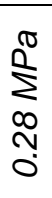 } & & 2.5 & 5.30 & N1 & N1 & N1 & N1 & N1 & 5.69 & 4.37 & N1 & 5.10 & 4.26 & N2 \\
\hline & $\frac{d}{2}$ & 5 & 4.03 & 3.36 & $\mathrm{~N} 1$ & $\mathrm{~N} 1$ & $\mathrm{~N} 1$ & $\mathrm{~N} 1$ & 4.74 & 3.70 & N1 & 4.98 & 4.04 & $\mathrm{~N} 2$ \\
\hline & $\frac{\pi}{1 \pi}$ & 10 & 3.61 & 3.25 & 1.99 & 3.55 & 2.91 & 2.85 & 3.61 & 2.63 & 1.55 & 4.50 & 3.36 & $\mathrm{~N} 2$ \\
\hline & & 20 & 3.08 & 2.69 & 1.80 & 2.72 & 2.66 & 1.98 & 1.78 & 2.24 & 0.99 & 2.84 & 2.02 & N2 \\
\hline
\end{tabular}

* the symbols "N1" - "N3" are explained in Table 4

\subsection{DATA PROCESSING}

We acquired three types of experimental data, which were processed separately. The image analysis results are dimensionless criteria that describe the breakup process. The stability was assessed to relate the spray quality with the internal flow, and finally, spray quality was judged by analyzing the droplet sizes.

\subsubsection{IMAGE ANALYSIS}

The dimensions and velocity of the observed liquid structures were measured from the visual record of the near-nozzle liquid structures. Image pre-processing consisted of cropping a raw image to remove unimportant data (Figure 4), with the field of view for the final images being $5.3 \times 4 \mathrm{~mm}$.

The velocity of droplets (and ligaments) was measured using a particle-tracking method (Figure 5). The area covered in the images was located very close to the discharge orifice, so the gas velocity was considered to be equal to the discharged gas velocity.

The air pressure at the output edge of the discharge orifice was considered to be $p_{\text {atm }}$ (atmospheric pressure). The air density at this point was calculated by the equation of state for an ideal gas (at $p_{\text {atm }}$ and gas temperature $20^{\circ} \mathrm{C}$ ). The gas velocity was then calculated from the measured gas mass flow. For the given working parameters of mixture discharge, choking conditions were not reached. 


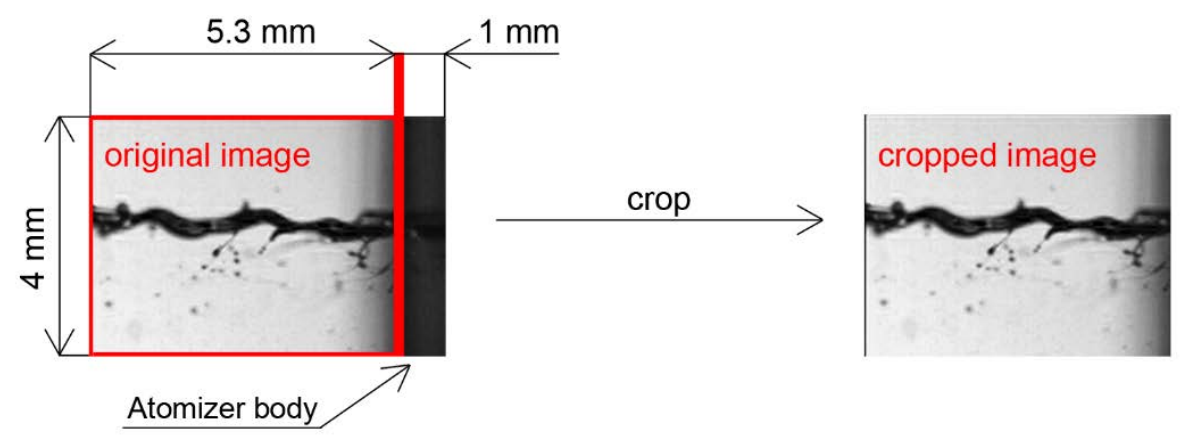

Figure 4. Image pre-processing
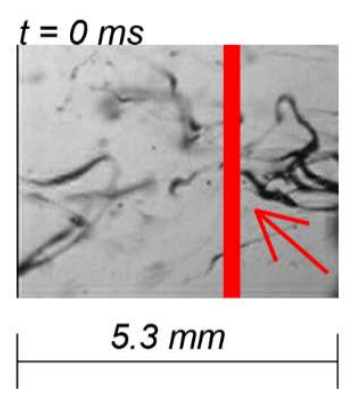
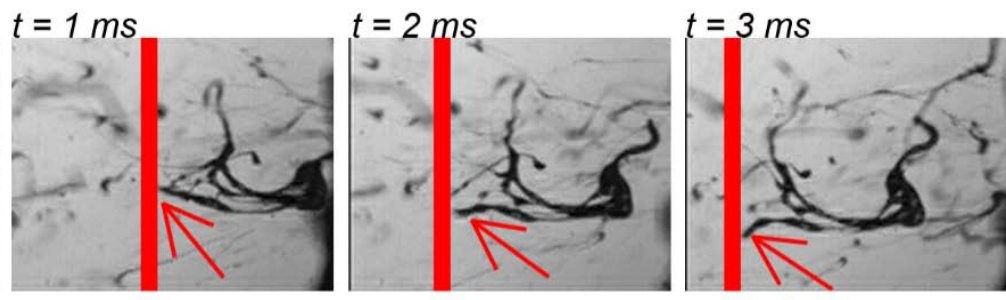

flow direction

Figure 5. Particle (ligament) tracking

Dimensionless criteria—such as the Reynolds $(\operatorname{Re}=\rho \cdot w \cdot D / \mu)$, Weber $\left(W e=\rho \cdot w^{2} \cdot D / \sigma\right)$ and Ohnesorge $\left(O h=W e^{1 / 2} / R e\right)$ numbers-were used to estimate the breakup regimes according to the work of Hinze (1955), Hsiang (1992) and Faeth (1995). These criteria were determined using the following flow parameters: the liquid-to-gas velocity difference $(w)$, the ligament diameter $(D)$ and the fluid's physical properties (Table 1). Once these parameters were known, the liquid breakup regime could be estimated using the breakup map introduced by Hinze (1955) and later verified by Hanson (1963), Loparev (1975), Krzeczkowski (1980), Hsiang and Faeth $(1992,1995)$.

\subsubsection{SPRAY STABILITY AND INTERNAL FLOW ANALYSIS}


In this study, the spray quality was judged based on the stability of the spray cone and droplet size. The stability (or steadiness) of the spray is often related to the inter-particle arrival time (Luong 1999, Jedelský 2012) and evaluated according to the multipoint statistical description of the dispersed flow developed by Edwards and Marx (1995). The spray cone stability described in this section is related to observed macroscopic changes in the spray cone. This assessment was based on the visual observation of the spray during the measurements, so it was a qualitative assessment. According to the spray cone stability, each spray was awarded either a number from 1 to 4 or one of symbols "N1", "N2" and "N3", all of which are described in Table 4.

Table 4. Assessment of spray cone stability

\begin{tabular}{ll}
\hline Symbol & Description of the observed spray behavior \\
\hline 1 & Stable spray cone, no pulsations were visually observed \\
\hline 2 & Occasional, weak pulsations were visually observed \\
\hline 3 & Regular pulsations can be visually observed, more noise produced \\
\hline 4 & Spray pattern changes rapidly, occasional liquid jet instead of the spray cone occurs \\
\hline $\mathrm{N} 1$ & No atomization, only liquid jet, occasional "explosion" of the gas bubble \\
\hline $\mathrm{N} 2$ & Discharge orifice is blocked by maltodextrin crystals, no liquid flow observed \\
\hline N3 & Atomizer cannot achieve this working regime \\
\hline
\end{tabular}

Spray stability was examined visually. This was related to the internal flow pattern, which could not be observed directly because the atomizers were not transparent. For the simple pipes, such as the mixing chambers of our atomizers, a substantial number of investigations were carried out to find the effect on the flow regime of the liquid's physical properties $(\sigma, \mu, \rho)$, the fluxes of the mixture components, and the geometry of the pipe. The fluid velocities inside the mixing chamber were determined from the measured hydraulic parameters (liquid and gas mass flows and $\Delta p$ ) using an online multiphase flow calculator (http://www.energetickeforum.cz/ext/2pf/discharge/). For these calculations, the gas density and the gas pressure inside the mixing chamber $\left(p_{\text {mix }}\right)$ needed to be known. The pressure inside the mixing chamber was expressed as $p_{\text {mix }}=\Delta p+p_{\text {atm }}-p_{\text {loss1 }}$, where ploss1 denotes the pressure loss between the gas pressure measurement point and the mixing chamber. When calculating the ploss1, we assumed no friction loss in the pipes because of the short distance between the 
measurement point and the atomizer's mixing chamber. The only substantial flow resistance was in the gas injector in the wall of the mixing chamber. This can be characterized as a circular orifice with sharp edges (i.e. a simple drilled hole). The maximum calculated ploss1 values were very low for each of the atomizers used: OIL $(0.0015 \%$ of $\Delta p)$, OIG $(0.003 \%)$, CFT $(0.049 \%)$, Yjet (2.1\%). We therefore neglected this pressure loss and used the value $\Delta p+p_{\text {atm }}$ to determine the mixing chamber gas density (for use in calculating flows inside the mixing chamber).

Spray stability was related to the internal flow of our atomizers. Since we could not investigate this experimentally, we determined the types of internal flows from the measured hydraulic parameters using the modified baker's map and the dimensionless parameter of internal flow $(\Phi)$.

\subsubsection{DROPLET SIZING}

Droplet sizes were measured with frequency $500 \mathrm{~Hz}$, and the measurement period was $25 \mathrm{~s}$ long. The whole time record therefore comprised 12,500 records of instantaneous SMD. The droplet sizes presented in Fig. 14 were calculated as mean values from this data set. The standard deviation (STD) of SMD was used to measure temporal SMD variations.

\section{RESULTS}

As mentioned in the introduction, this study uses the liquid breakup character, spray stability and droplet size as the criteria for comparing the investigated atomizers. The dimensionless criteria (We, Oh) were used to determine the breakup regime and its influence on the spray pattern in Section 3.1. The following section, 3.2, deals with the investigation of the internal flow and its influence on spray stability.

\subsection{LIQUID BREAKUP AND SPRAY PATTERN}

The liquid breakup mechanism discussed in this section depends on the interaction between viscous, surface tension and air drag forces. The near-nozzle flow pattern consists of liquid structures, namely droplets and fibres (ligaments, filaments), which are deformed by these forces. 
The We values were calculated from our experimental data and found to be in range of 2-10 for all measured regimes with the OIG, OIL and CFT atomizers, indicating the dominant effect of drag force over surface tension. When $\sigma$ is not the dominant factor, the liquid can create long, thin threads before they break up into spherical droplets through the Rayleigh mechanism. The results of the image processing (Figure 6) also show the weak influence of operating pressure and atomizer type on $O h$. For both the $\Delta p$ values, Oh was primarily controlled by the liquid's viscosity. For the MD50 liquid, $O h=0.3-0.6$, while for the MD45 liquid, $O h=0.9-1.5$, and with the MD40 liquid, $O h=1-2$. When the viscosity (and consequently $O h$ ) increases, the deformation is slower. In turn, because the deformation time increases, the breakup occurs further from the discharge orifice (Hsiang, 1992). Our assumptions from this analysis were as follows:

- The investigated spray may contain ligaments rather than droplets (for OIG, OIL, and CFT and $W e=2-10)$.

- The length of ligaments increases with viscosity.

- Long ligaments can appear further away from the discharge orifice for more viscous liquids, and they may break into spherical droplets outside of the visualized region.

Our observations agreed well with these. The near-nozzle spray for the most viscous liquid (MD50) contained long, branched ligaments (Figure 7). An increase in the GLR caused ligament shortening. For our range of $\Delta p$, no significant change of the spray pattern was observed in most cases (only for MD50 liquid). As the viscosity decreased to $143 \mathrm{mPa} \cdot \mathrm{s}$ (MD45, Figure 8), the ligaments became shorter and less branched than in the previous case. The decrease in the GLR led to their elongation and branching. The spray pattern for the MD40 liquid (Figure 9) was characterised by the presence of short, thin liquid threads, with long threads forming at GLRs of $2.5 \%$ and $5 \%$. For both variants of the effervescent atomizer (OIG, OIL), the spray was composed of ligaments that shortened with an increasing GLR. We also observed the presence of spherical droplets when the GLR was $20 \%$. The CFT atomizer produced the greatest number of long threads from all of the tested atomizers, specifically with the MD40 liquid. This was especially true with an inlet pressure of $0.14 \mathrm{MPa}$, when liquid mass was concentrated near the nozzle axis. The values of We for the Y-jet atomizer were significantly lower (from 0.1 to 3 ). This indicates that for some of the measured regimes at $\Delta p=0.14 \mathrm{MPa}(\mathrm{GLR}=5,-20 \%, \mathrm{MD} 40$ and MD45) and $\Delta p=0.28 \mathrm{MPa}$ (GLR $=20 \%$, Figure 8), surface tension became the dominant factor. We assumed 
that under these conditions, spherical droplets are more likely to form in the near-nozzle area than with the other atomizers.

The observations showed that the $\mathrm{Y}$-jet atomizer produced a spray similar to the previous experiments with the MD50 liquid (Figure 7). The ligaments were long and branched, and no spherical droplets appeared. The liquid threads were also present further from the discharge orifice due to the longer deformation time caused by high viscosity. Shorter ligaments appeared as the GLR decreased. For the liquid with a viscosity of $143 \mathrm{mPa} \cdot \mathrm{s}$ (MD45, Figure 8), this atomizer produced larger ligaments than the other atomizers, especially at $\Delta p=0.14 \mathrm{MPa}$. Spherical droplets appeared at GLR $=20 \%$ at both pressures, which accords with the estimated We. When the viscosity decreased to $60 \mathrm{mPa} \cdot \mathrm{s}$, the atomizer produced long ligaments at GLRs of $2.5 \%$ and $5 \%$, while only short ligaments and droplets were present in the near-nozzle spray at GLRs of $10 \%$ and $20 \%$.

Some general remarks can summarize the above results:

- The Oh was mainly influenced by the liquid's viscosity. The effect of atomizer design and working parameters was negligible in comparison (Fig. 6).

- Atomizer design did not influence the range of the observed We value for the OIG, OIL, and CFT atomizers. The Y-jet atomizer produced a spray with a considerably lower We range (Fig. 6) due to the low gas-to-liquid velocity difference in the observed region.

- Inlet pressure influenced the liquid pattern only with the MD40 and MD45 liquids.

- The GLR had the most significant effect on the spray pattern, regardless of which atomizer, liquid, or working parameters were used. 

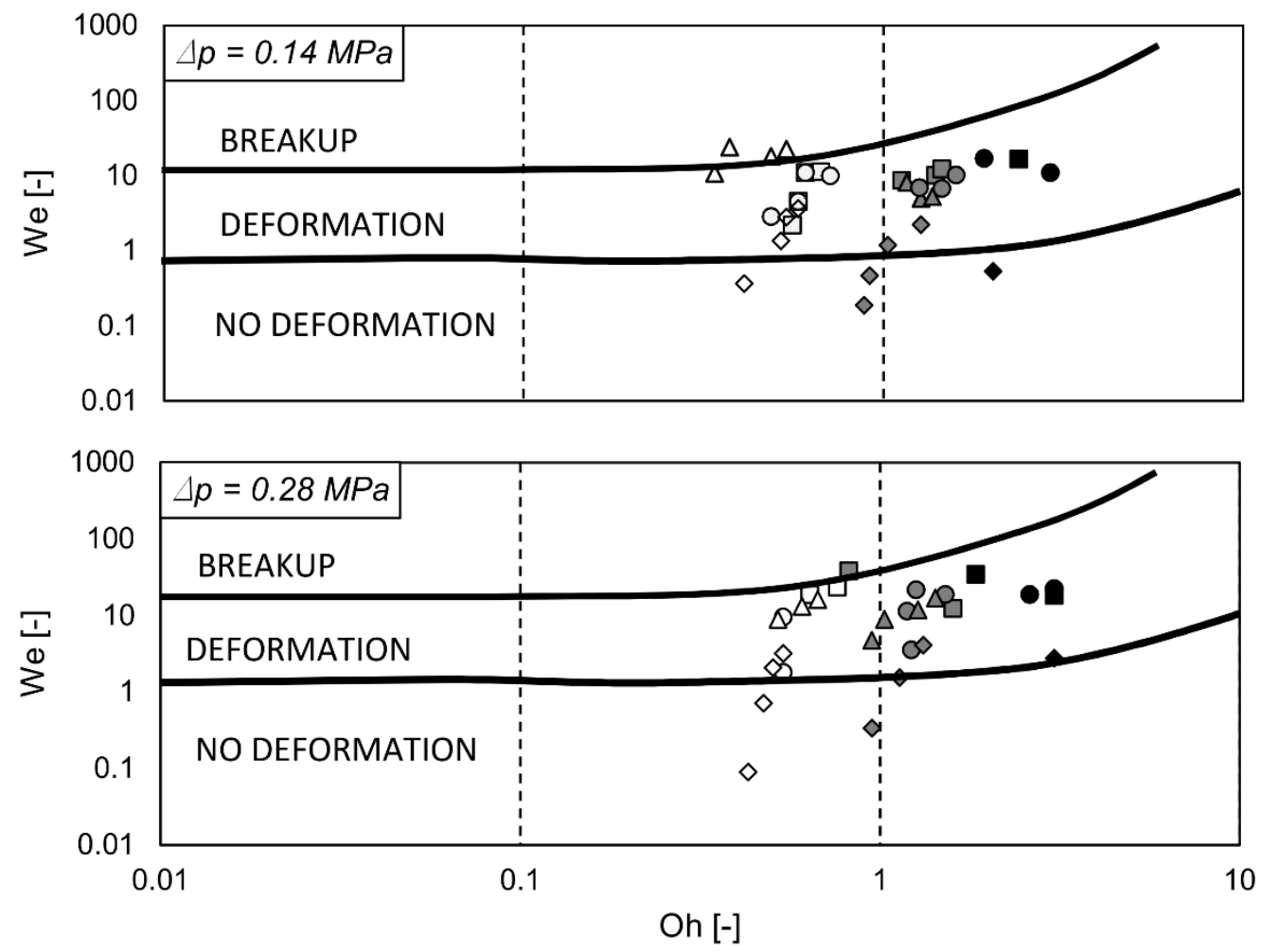

口OIG, MD40 पOIG, MD45

OOIL, MD40 OOIL, MD45

-OIG, MD50

$\diamond \mathrm{Y}$ - jet, MD40 $\diamond \mathrm{Y}$-jet, MD45

OIL, MD50

$\triangle \mathrm{CFT}, \mathrm{MD} 40 \quad \triangle \mathrm{CFT}, \mathrm{MD} 45$

$\bullet$ Y-jet, MD50

Figure 6. Liquid breakup regimes (The breakup regimes' transitions curves were adapted from Faeth (1995)) 


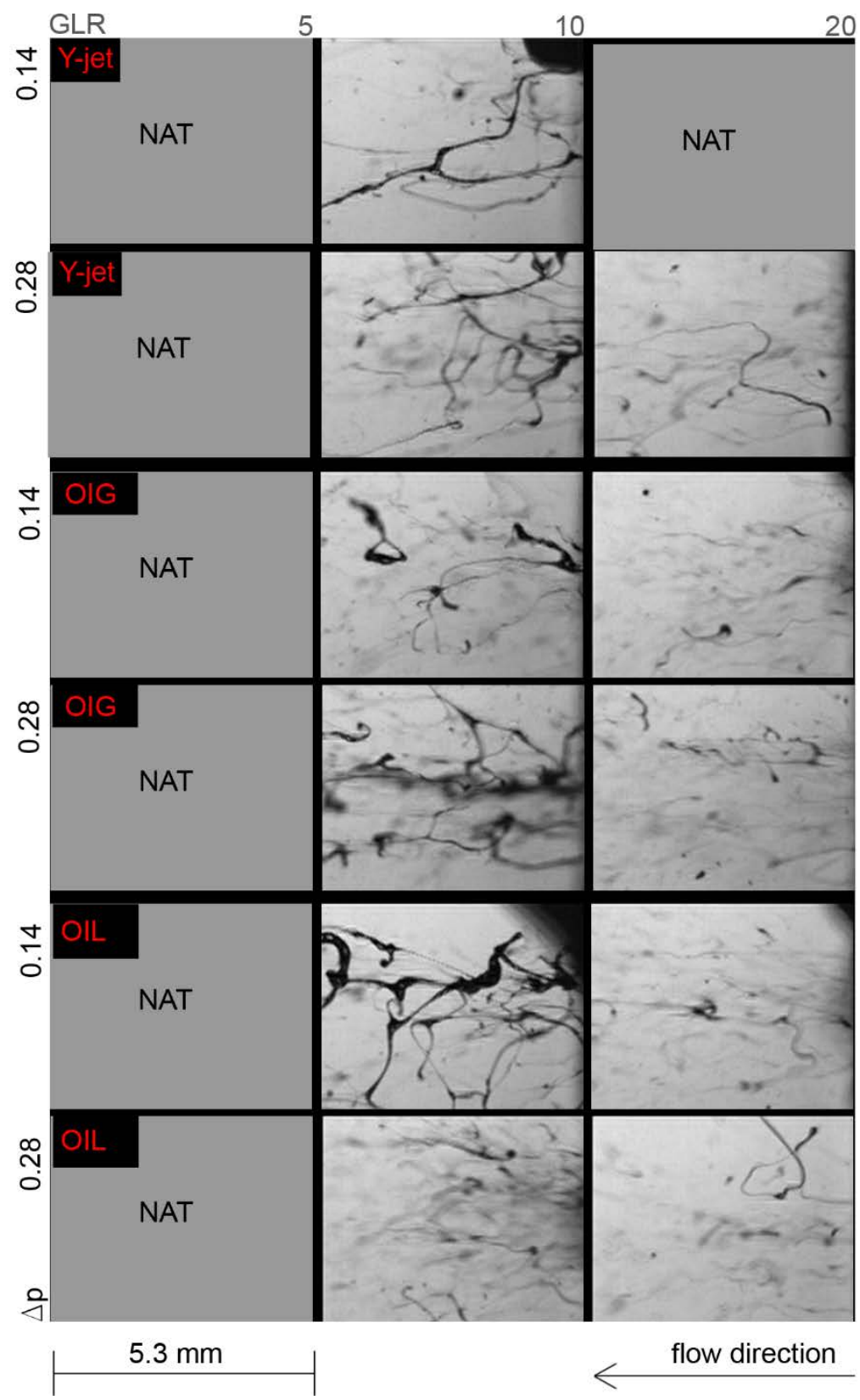

Figure 7. Near-nozzle spray pattern for $\mu=308 \mathrm{mPa} \cdot \mathrm{s}, \Delta p$ [MPa], GLR [\%]. NAT denotes regimes where liquid was not atomized. 


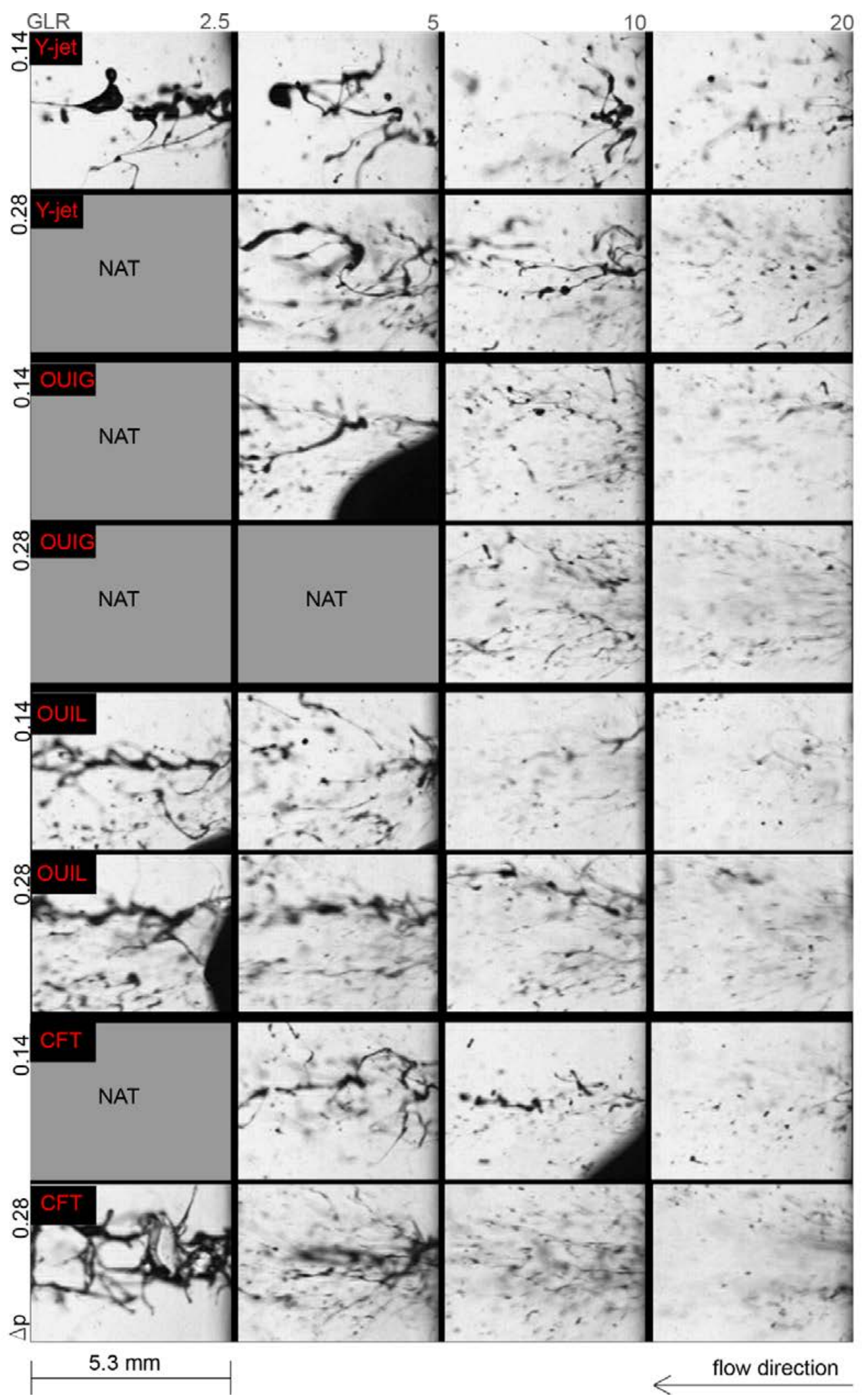

Figure 8. Near-nozzle spray pattern for $\mu=143 \mathrm{mPa} \cdot \mathrm{s}, \Delta p$ [MPa], GLR [\%]. NAT denotes regimes where liquid was not atomized. 


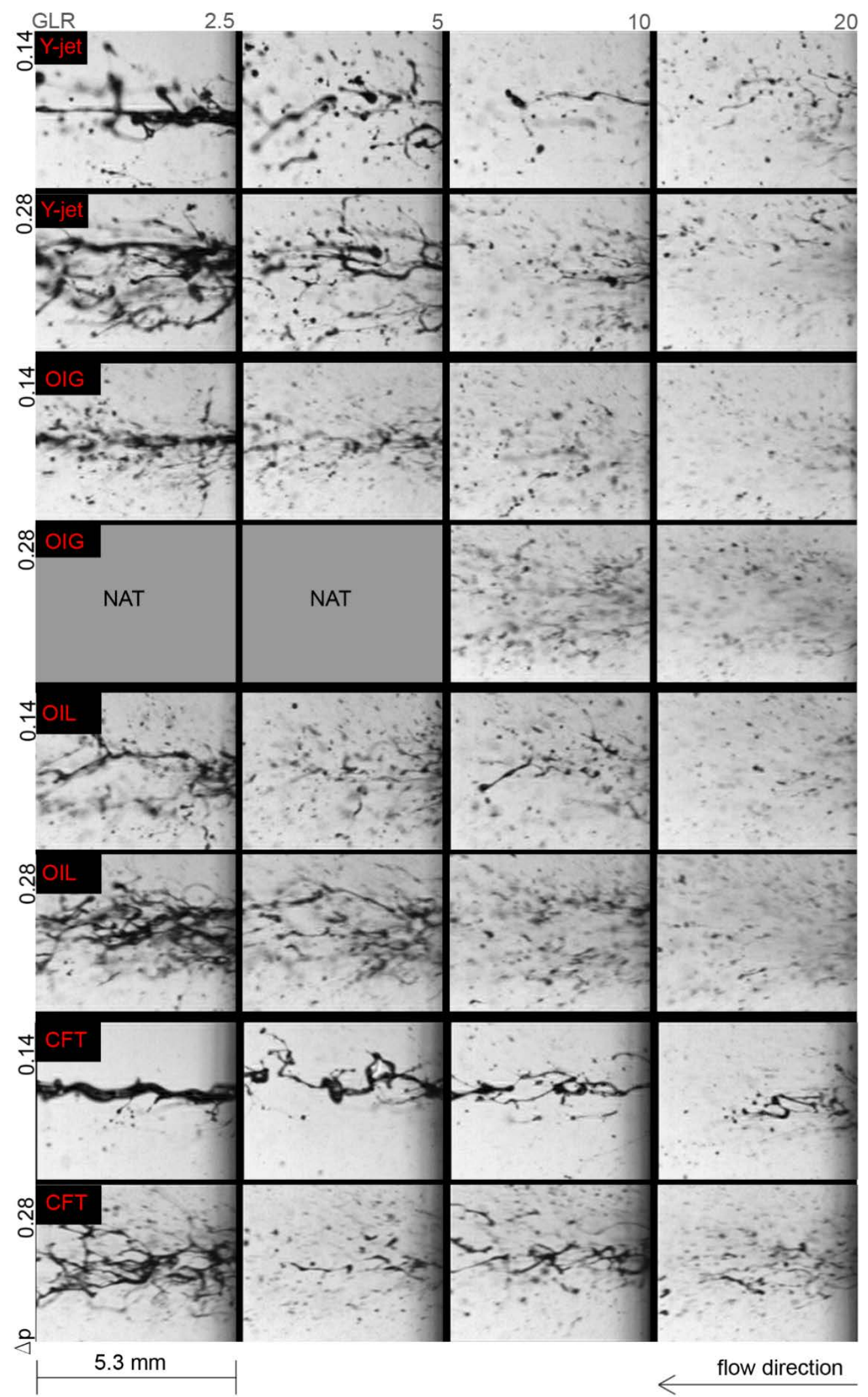

Figure 9. Near nozzle spray pattern for $\mu=60 \mathrm{mPa} \cdot \mathrm{s}, \Delta p$ [MPa], GLR [\%]. NAT denotes regimes where liquid was not atomized. 


\subsection{SPRAY STABILITY AND INTERNAL FLOW}

This evaluation was based on qualitative observations of spray stability during the experiments.

The spray stability assessment is summarized in Table 5, according to the criteria in Table 3.

Table 5. Spray cone stability

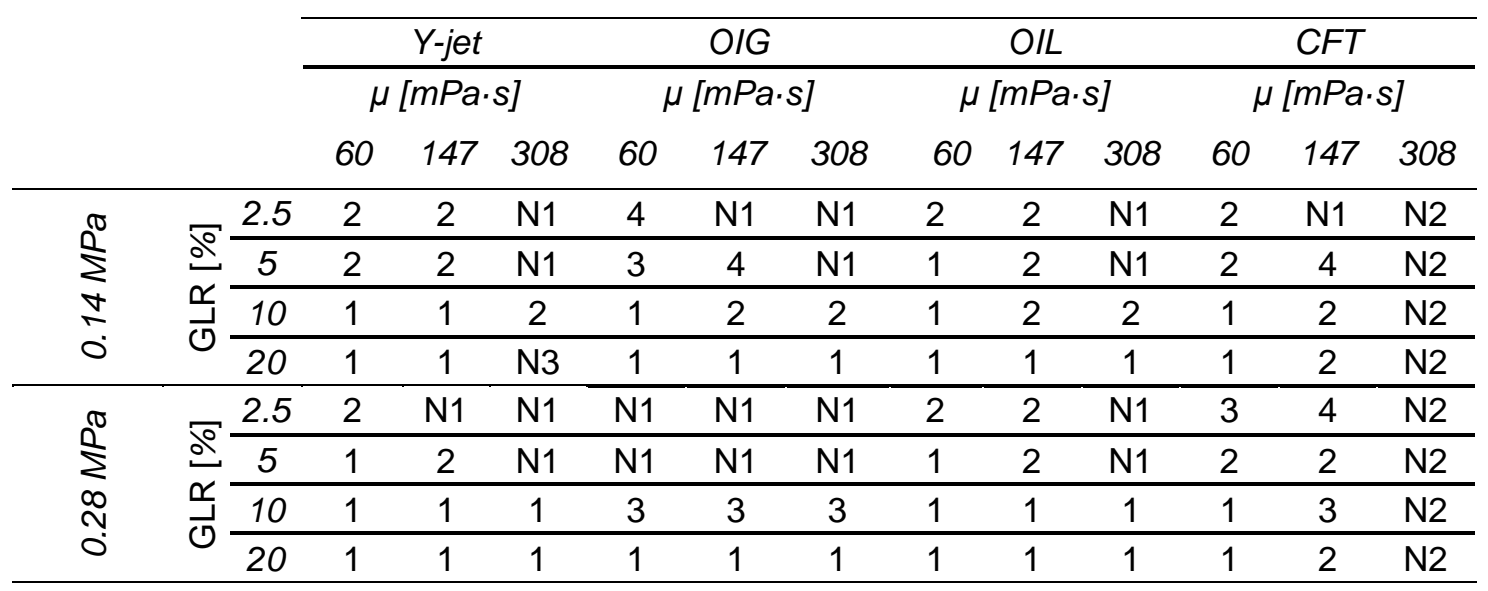

The Y-jet atomizer produced stable sprays for the low-viscosity liquids (MD45, MD40) at GLRs of $10 \%$ and $20 \%$ (for both inlet pressures). For GLRs of $2.5 \%$ and $5 \%$, occasional spray cone pulsations were observed. The spray was stable at $\Delta p=0.28 \mathrm{MPa}$ and a GLR of $10 \%$ or $20 \%$ with the MD50 liquid. For low GLR values with MD50, a liquid jet was observed instead of a developed spray cone. Atomization at $\Delta p=0.14 \mathrm{MPa}$ was only observed for a GLR of $10 \%$. This atomizer was not able to achieve a working regime with $\Delta p=0.14 \mathrm{MPa}$ and a GLR of $20 \%$ when using the MD50 liquid.

The OIG atomizer produced a stable spray at a GLR of $20 \%$ only, although this worked for both pressures and all liquids. At a GLR of $10 \%$, occasional $(\triangle p=0.14 \mathrm{MPa})$ or regular $(\Delta p=0.28 \mathrm{MPa})$ pulsations were observed. The atomizer failed to atomize any of the liquids at a GLR of $2.5 \%$ or $5 \%$ and when $\Delta p=0.28 \mathrm{MPa}$. 
The OIL atomizer worked well with the MD45 and MD40 liquids, but it did not work with the MD50 liquid and a GLR of $2.5 \%$ or $5 \%$ for both inlet pressures. The spray produced with GLRs of $10 \%$ and $20 \%$ was stable for both pressures and all liquids.

The CFT atomizer was unable to work with the maltodextrin solution with $\mu=308 \mathrm{mPa} \cdot \mathrm{s}$ (MD50). After a very short working time (seconds), maltodextrin crystals blocked the discharge orifice. Any further attempt to atomize this liquid with the CFT atomizer was unsuccessful. MD45 spraying, meanwhile, could be described as unstable for all of the working regimes. The atomizer produced stable sprays at GLRs of $10 \%$ and $20 \%$ for both pressures when the low-viscosity liquid was used (MD40).

It is well-known that the internal two-phase flow pattern influences the external flow (Buckner 1991, Santangelo 1995, Song 1996) and therefore the spray stability. As we could not examine the flow in the mixing chamber experimentally, we determined the internal flow using the available experimental results from other researchers.

In the work of Song (1996), the internal flow of the Y-jet atomizer was evaluated in terms of the liquid-to-gas momentum ratio (Figures 10 and 11, section 1). When the gas momentum was dominant $(\Phi<1)$, the liquid would create a film on the mixing chamber wall just after leaving the liquid port. When the liquid momentum was comparable to the gas momentum $(1<\Phi<3)$, mixing took place in the central part of the mixing chamber, and the liquid was dispersed into the gas stream. When the liquid momentum overcame the gas momentum $(\Phi>3)$, the liquid stream reached the wall opposite the liquid port and created a liquid film, similar to in the first case. The results comparison (Figure 10 and Table 4) shows that for $\Phi>1$ (i.e. GLRs of $2.5 \%$ and $5 \%$ ), the spray either became less stable (with MD40/MD45) or no spray was produced (with MD50). These working regimes were characterized by intense liquid-gas interaction (i.e. deflection of the gas stream by the liquid). This interaction can produce gas pulsations in the mixing chamber, which influences spray stability. A stable spray was produced for $\Phi<1$, because the liquid stream formed the film on the wall just after reaching the mixing chamber, so it did not cause air stream deflections. This flow pattern was stable with low temporal fluctuations in the GLR, which led to stable spray generation. 


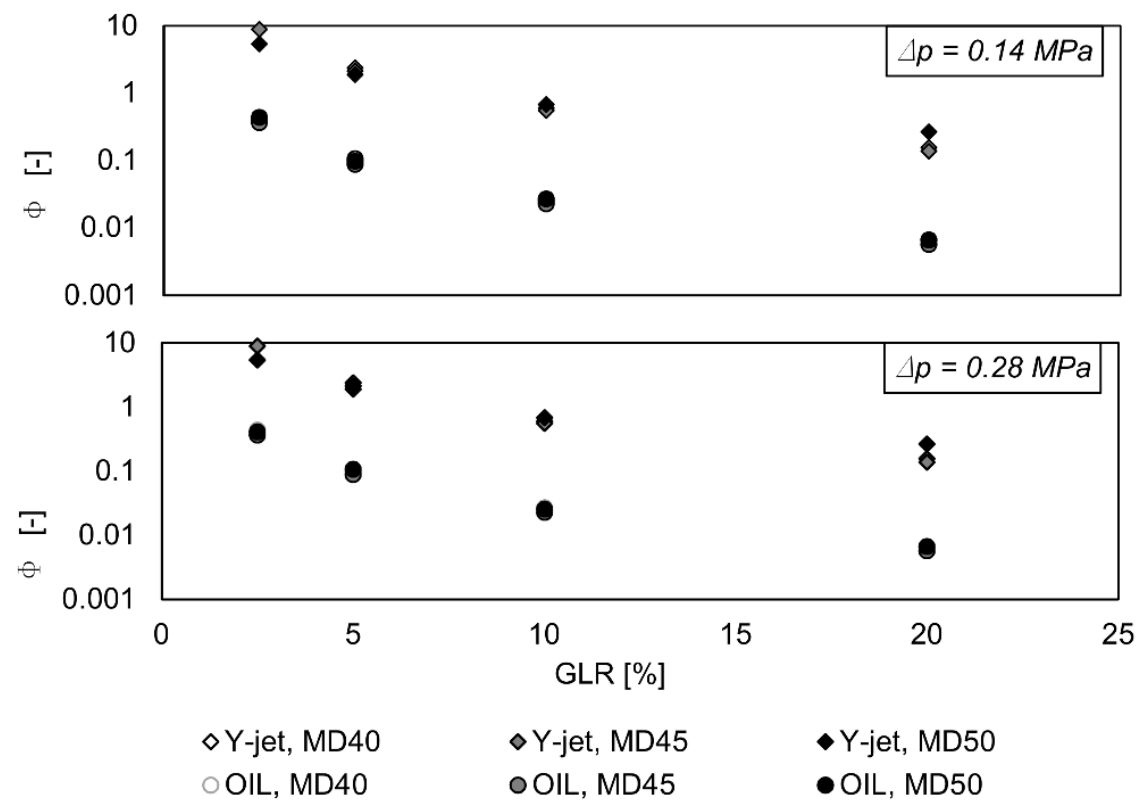

Figure 10. Comparison of the gas-to-liquid momentum ratio for the OIL and Y-jet atomizers

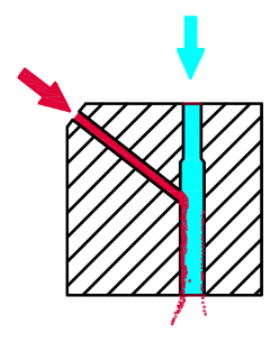

$\Phi<1$

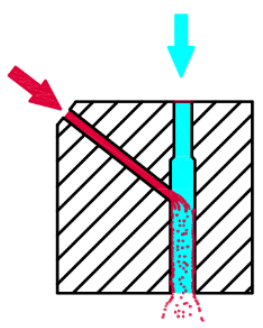

$1<\Phi<3$

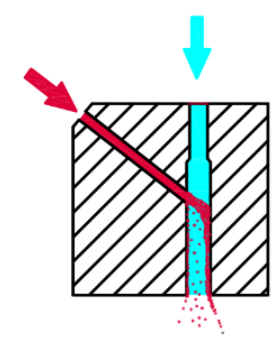

$\Phi>3$

Figure 11. Estimated internal flow of the Y-jet atomizer (according to Song (1996))

There is no work investigating the influence of $\Phi$ on the OIG atomizer's internal flow, so an online calculator (http://www.energetickeforum.cz/ext/2pf/maps/) with the modified baker's map was used to determine the flow regime of this atomizing device (Table 5). Although this map was designed for fully developed multiphase flows that are not actually achieved in the mixing chamber, we used it because of its simplicity. The internal flow at GLRs of $2.5 \%$ and $5 \%$ was estimated as a plug flow (Figure 12). The plug flow indicates local fluctuations in the GLR inside the discharge orifice, which leads to an unstable spray (Lorcher 2003). For the regimes 
$\Delta p=0.14 \mathrm{MPa}, \mathrm{GLR}=2.5 \%(\mathrm{MD} 40)$ and $\mathrm{GLR}=2.5$ and 5\% (MD40, MD45), it was observed that the OIG atomizer did not atomize the examined liquids at GLRs under 5\%. The atomizer's work for these regimes was characterized by long periods of only liquid being ejected from the discharge orifice, followed by short ejections of gas (with no liquid). This was the result of the inhomogeneous internal flow. The flow regimes at a GLR of $10 \%$ were identified as plug or slug flows. Slug flows contain large bubbles comparable in size to the diameter of the mixing chamber, separated by thin liquid layers. The passage of the liquid layers through the discharge orifice caused local fluctuations in the GLR, which led to an unstable spray. For increased $\Delta p$, the air in the mixing chamber was more compressed, so its void fraction decreased. The larger fraction of the liquid caused a thicker liquid film, separating the plugs and the slugs, so the GLR fluctuations and consequent pulsations were more intense when $\Delta p=0.28 \mathrm{MPa}$. Only slug flow was predicted for the working regimes with a GLR of $20 \%$. When the void fraction increased, the slugs were divided into progressively thinner liquid films, so local fluctuations in the GLR in the discharge orifice became less intense.

Table 6. Internal flow patterns of the OIG and OIL atomizers, estimated using the baker's map

\begin{tabular}{|c|c|c|c|c|c|c|c|}
\hline & & \multicolumn{3}{|c|}{$\Delta p=0.14 \mathrm{MPa}$} & \multicolumn{3}{|c|}{$\Delta p=0.28 \mathrm{MPa}$} \\
\hline & & \multicolumn{3}{|c|}{$\mu[\mathrm{mPa} \cdot \mathrm{s}]$} & \multicolumn{3}{|c|}{$\mu[\mathrm{mPa} \cdot \mathrm{s}]$} \\
\hline & & 308 & 147 & 60 & 308 & 147 & 60 \\
\hline \multirow{4}{*}{$\frac{\sqrt{0}}{\frac{\alpha}{0}}$} & 2.5 & Plug & Plug & Plug & Plug & Plug & Plug \\
\hline & 5 & Plug & Plug & Plug & Plug & Plug & Plug \\
\hline & 10 & Plug & Slug & Slug & Plug & Slug & Plug \\
\hline & 20 & Slug & Slug & Slug & Slug & Slug & Slug \\
\hline
\end{tabular}

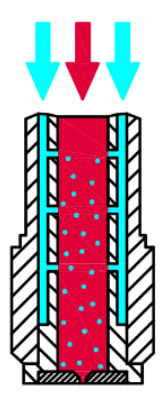

bubbly

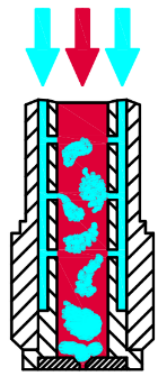

plug

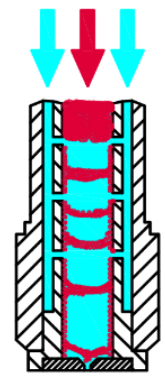

slug

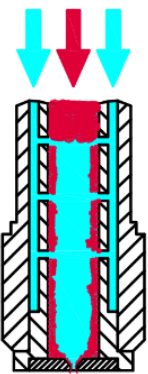

annular 
Figure 12. Two-phase flow patterns

Our experimental results indicate that changing the effervescent atomizer from an OIG to an OIL configuration improves spray stability. The OIL atomizer's spray was stable for almost all of the measured working parameters and atomized liquids, with the exception being the regimes with GLRs of $2.5 \%$ or $5 \%$ with the MD50 liquid. For both of the effervescent atomizer configurations (Table 3), the same internal flow patterns were estimated. This indicates that the mixing mechanism influences the internal flow of this atomizer, so its evaluation using only the baker's map is not suitable. To involve the mixing mechanism, we used $\Phi$, which was formerly applied to the Y-jet atomizer. For $\Phi<1$, (i.e. all investigated working regimes of the OIL atomizer), the liquid was unable to penetrate to the central portion of the mixing chamber. It formed a film on the wall, while the gas formed a core in the central portion (Figure 13). This flow pattern was stable with small temporal fluctuations in the GLR and led to a stable spray.

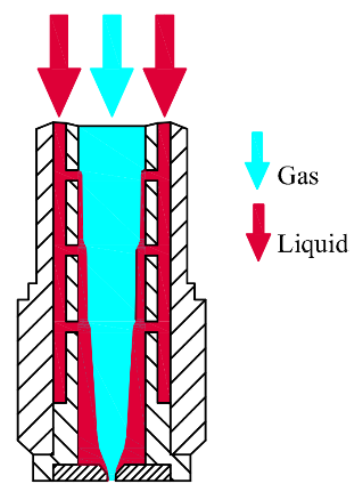

Figure 13. The estimated two-phase flow for the OIL atomizer

The flow pattern in the mixing chamber of the CFT atomizer was difficult to determine without experimental observation. The interaction between the two liquid streams probably produced random liquid structures, which were then deformed by the gas's drag force. The presence of maltodextrin crystals when using the MD50 liquid indicates that the liquid spent sufficient time in the mixing chamber to become dry and form crystals. 
The liquid was atomized into fragments whose size reduced as the relative velocity of the liquid and gas increased. The droplet size for all atomizers therefore significantly decreased with an increase in the GLR, as shown in Fig. 14 and a number of other publications (Whitlow 1993, Sher 2000, Sovani 2001). A similar trend in SMD reduction, although not as strong and systematic, was found for increasing pressure.

The OIL atomizer produced a spray with the smallest SMD at low GLRs and a fine spray for all other cases with MD40 and MD45. It also sprayed well with MD50 at GLRs of $10 \%$ and $20 \%$, but it failed to atomize this liquid at lower GLRs. The spray stability, in terms of the STD of droplet size (Tab. 7), was the best among the tested atomizers for all cases and with each liquid. This agrees well with the visual observations.

Among the set of tested atomizers, the spray with the best average drop size and stability was generally acquired with the $\mathrm{Y}$-jet atomizer. It produced stable sprays for the less viscous liquids (MD40, MD45), with even a slightly lower SMD at high GLRs than with the OIL atomizer.

The SMD and stability data for the OIG atomizer were below (MD40) or around (MD45) the average of the set. It performed similarly to the OIL and Y-jet atomizers for the MD50 liquid, which none of the atomizers were able to atomize for the full GLR range.

The CFT atomizer, as mentioned earlier, was only able to spray MD40 and MD45 liquids with average or subnormal $(M D 40)$ or poor (MD45) stability and large SMD at low GLRs, with the lowest SMD being found at a high GLR.

The results show a positive correlation between the SMD and the STD of droplet size (spray stability). The unsteady discharge was characterised by a poor gas-liquid mixture, where the gas could not fully act upon the liquid mass and break it up. In addition, the available inlet energy was not used efficiently in the atomization process. 

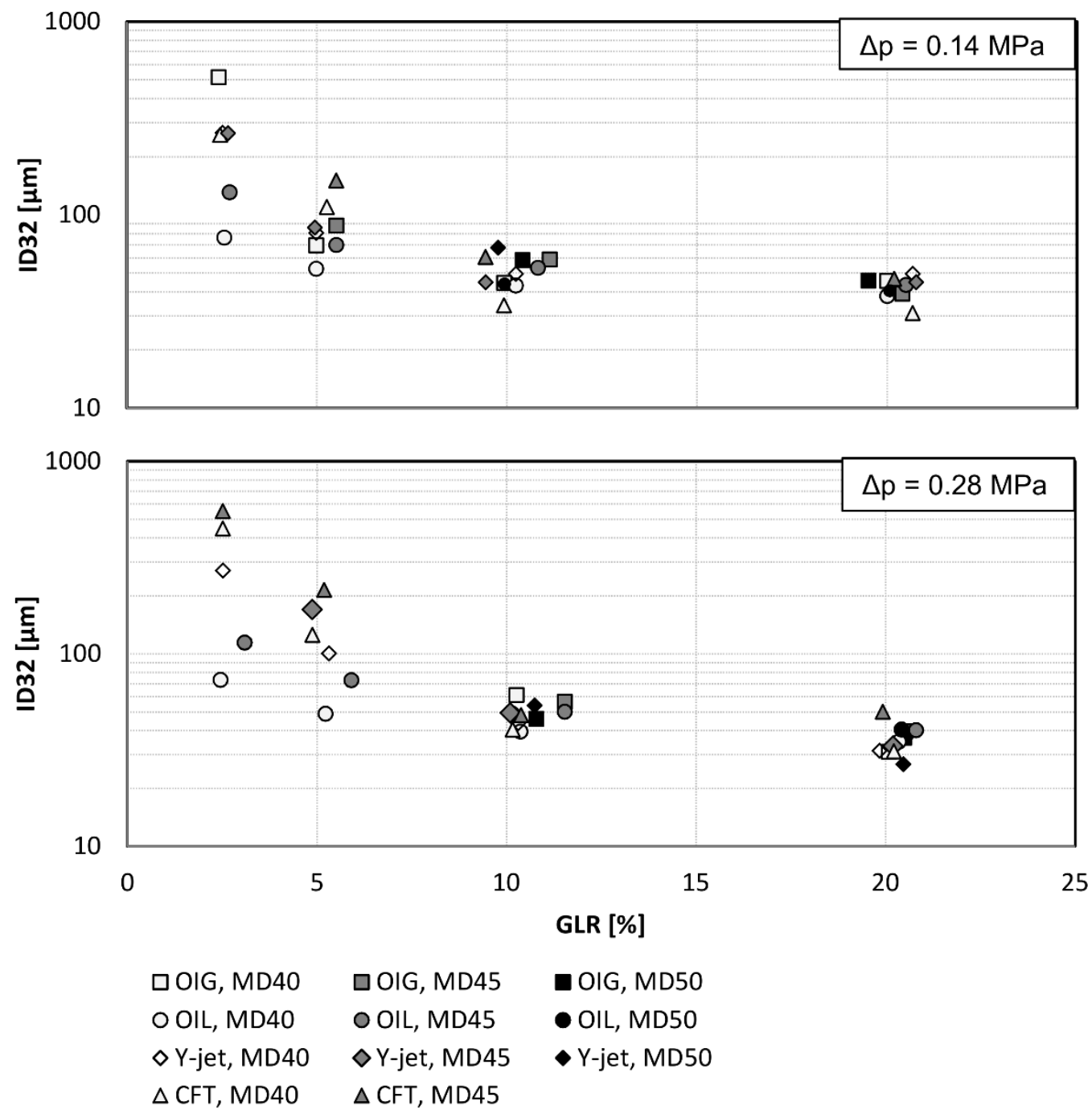

Figure 14. Measured Sauter mean diameter at $100 \mathrm{~mm}$ downstream of the discharge orifice, measured only for regimes with well-developed sprays

Table 7. Calculated standard deviations of SMD $[\mu \mathrm{m}]$

\begin{tabular}{|c|c|c|c|c|c|c|c|c|c|c|c|c|c|}
\hline & & \multicolumn{3}{|c|}{ Y-jet } & \multicolumn{3}{|c|}{ OIG } & \multicolumn{3}{|c|}{ OIL } & \multicolumn{3}{|c|}{ CFT } \\
\hline & & \multicolumn{3}{|c|}{$\mu[\mathrm{mPa} \cdot \mathrm{s}]$} & \multicolumn{3}{|c|}{$\mu[\mathrm{mPa} \cdot \mathrm{s}]$} & \multicolumn{3}{|c|}{$\mu[\mathrm{mPa} \cdot \mathrm{s}]$} & \multicolumn{3}{|c|}{$\mu[\mathrm{mPa} \cdot \mathrm{s}]$} \\
\hline & & 60 & 147 & 308 & 60 & 147 & 308 & 60 & 147 & 308 & 60 & 147 & 308 \\
\hline \multirow{4}{*}{$\underset{\substack{\sigma \\
\underset{\sim}{J}}}{\stackrel{\sigma}{\sim}}$} & 2.5 & 64 & 77 & N1 & 520 & N1 & N1 & 6 & 27 & N1 & 150 & N1 & N2 \\
\hline & $\lesssim \longdiv { 5 }$ & 10 & 13 & N1 & 17 & 9 & N1 & 3 & 8 & N1 & 42 & 44 & N2 \\
\hline & 10 & 5 & 5 & 54 & 6 & 5 & 10 & 3 & 6 & 6 & 7 & 14 & $\mathrm{~N} 2$ \\
\hline & 20 & 5 & 5 & N3 & 7 & 4 & 10 & 3 & 4 & 5 & 5 & 4 & $\mathrm{~N} 2$ \\
\hline \multirow{3}{*}{ 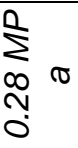 } & 2.5 & 51 & N1 & N1 & $\mathrm{N} 1$ & N1 & N1 & 4 & 8 & N1 & 354 & 434 & $\mathrm{~N} 2$ \\
\hline & 5 & 11 & 33 & N1 & $\mathrm{N} 1$ & $\mathrm{~N} 1$ & $\mathrm{~N} 1$ & 2 & 5 & N1 & 165 & 232 & $\mathrm{~N} 2$ \\
\hline & (1) 10 & 4 & 5 & 7 & 15 & 3 & 18 & 2 & 4 & 5 & 8 & 11 & $\mathrm{~N} 2$ \\
\hline
\end{tabular}




\begin{tabular}{lllllllllllll}
20 & 4 & 5 & 4 & 3 & 3 & 5 & 2 & 3 & 4 & 5 & 13 & $\mathrm{~N} 2$ \\
\hline
\end{tabular}

\section{CONCLUSIONS}

We have compared the performance of four different twin-fluid atomizers using several experimental methods with a set range of operating conditions and three liquids with differing viscosities. The tests revealed significant differences between all the nozzles, with none being able to achieve satisfactory performance for the full range of operating conditions. These results can be used to establish their potential applications, with each atomizer being suitable for different regimes, liquids and tasks.

The flow inside the Y-jet atomizer was estimated according to the liquid-to-gas momentum ratio. When accelerated by the high-velocity gas, the liquid either adhered to the wall $(\Phi<1, \Phi>3)$ or dispersed into the gas stream $(1<\Phi<3)$. The gas-liquid mixture reached the discharge orifice at a lower liquid-to-gas velocity slip when compared to the other atomizers tested. The discharge was therefore realized at low We. Low temporal fluctuations in the internal flow resulted in a stable spray for a wide range of working parameters. The Y-jet atomizer, according to our SMD results, produced larger droplets than the effervescent atomizers, especially at low GLRs. This is most likely the result of a low gas-to-liquid velocity difference in the near-nozzle region.

We observed significant differences in the sprays produced by the two effervescent atomizer configurations (OIG and OIL). The internal flow regimes of the OIG atomizer were determined to be plug or slug flows, while one type of internal flow was determined inside the OIL atomizer, with a liquid film flowing along the wall separately from the gas core.

The OIL atomizer therefore produced spray with small pulsations, while the spray stability of OIG atomizer was worse and decreased at higher pressure and lower GLRs. The gas was accelerated rapidly during the discharge due to the reduced flow cross-section from the mixing chamber to the discharge orifice. The liquid also accelerated less, leading to a larger velocity slip than in the previous case. The discharge appeared with $W e=2-10$ for both 
configurations. As the result, the OIL atomizer produced small droplets with low temporal SMD variations, even at low GLRs. The observed pulsations in the OIG spray at a low GLR caused the presence of large droplets in the spray and an increased SMD.

The Y-jet and OIL atomizers produced the most stable sprays, regardless of $\Delta p$ and GLR, with liquids up to $\mu=147 \mathrm{mPa} \cdot \mathrm{s}$. However, they were unable to atomize the more viscous liquids at GLRs under 5\%. These nozzles are suitable for liquid combustion (e.g. oil boilers and industrial furnaces) and spray drying in the food industry. The more stable and finer spray produced by the OIL atomizer, according to our drop size data, suggests it is most suitable for applications where spray stability under a wide range of operation conditions is essential, such as in gas turbines and scramjet engines. Moreover, due to its symmetrical design, this atomizer generates a more uniform spray than the $\mathrm{Y}$ - jet atomizer. However, in a multi-hole configuration, the $\mathrm{Y}$-jet atomizer could perform better, because no interaction and gravitational flow separation can occur among the individual exit orifices, especially in the case of horizontal adjustment. The low We observed in the near-nozzle Y-jet spray suggests a fully developed spray close to the exit orifice, indicating a suitability for applications where a short nozzle-to-target distance is required.

The CFT atomizer was found to be the only tested device that was highly sensitive to the liquids' viscosity. It was completely unable to atomize the most viscous liquid (MD50). With the MD45 liquid, it mostly produced an unstable spray, regardless of the working parameters. It did give a stable spray for the MD40 liquid, but only with a high GLR. The SMD for the stable regimes was lower than for the other atomizers, which shows this nozzle is the most suitable for lower viscosity liquids. This atomizer could be used in applications that benefit from an unsteady spray, such as in some consumer products because of the increased air entrainment rate (Liu 2011) or in spray-cooling technologies with pulsed sprays (Panao 2005). It cannot be used for spray drying, because maltodextrin crystals form from the intense contact of the solution with air inside the nozzle, subsequently choking the discharge orifice. The atomization of non-parching liquids could be successful, but new tests are required. The CFT atomizer was developed recently, and there has been little time to study it. The present configuration requires further development, because due to the number of its design parameters, it still offers a potential for improvement. 


\section{ACKNOWLEDGEMENT}

The authors acknowledge the financial support from project No. GA15-09040S, which was funded by the Czech Grant Agency, project LO1202 NETME CENTRE PLUS with financial support from the Ministry of Education, Youth and Sports of the Czech Republic under the "National Sustainability Programme I" and project No.CZ.1.07/2.3.00/30.0005 of the Education for Competitiveness Operational Programme of the Ministry of Education, Youth and Sport of the Czech Republic.

\section{REFERENCES}

Baker, O. (1954). "Simultaneous Flow of Oil and Gas", Oil and Gas Journal, vol. 53, pp.185-195

Barnea, D. (1987). "A unified model for predicting flow-pattern transitions for the whole range of pipe inclinations", Int. J. Multiphase Flow, vol. 13, DOI: 10.1016/0301-9322(87)90002-4

Barroso J., Lozano A., Barreras F., Lincheta. (2014). "Analysis and prediction of the spray produced by an internal mixing chamber twin-fluid nozzle", Fuel Processing Technology, vol. 128, ISSN 0378-3820

Brennen C. E. (2005). "Fundamentals of two-phase flows", Cambridge university press, ISBN 0521848040

Broniarz-Press L., Ochowiak M., Rozanski J., Woziwodzki S. (2009). "The atomization of wateroil emulsions", Experimental Thermal and Fluid Science, vol. 33(6), pp. 955-62

Broniarz-Press L., Ochowiak M., Woziwodzki S. (2010). "Atomization of PEO aqueous solutions in effervescent atomizers", International Journal of Heat and Fluid Flow, vol. 31(4), pp. $651-658$.

Buckner H.N, Sojka P.E., Lefebvre A.H. (1990). "Effervescent Atomization of Coal-Water Slurries", ASME Publ. PD-30, pp. 105-8. 
Buckner H.N., Sojka P.E. (1991). "Effervescent atomization of high-viscosity fluids. Part 1: Newtonian liquids", Atomization and Sprays, vol. 1(3), pp. 239-52

Daviault S.G., Ramadan O.B., Matida E.A., Hughes P.M., Hughes R. (2012). "Atomization performance of petroleum coke and coal water slurries from a twin fluid atomizer", Fuel. Vol. 98, pp. 183-93

Edwards C. F., Marx K. D. (1995). "Statistical structure of the ideal spray. Part I: Fundamental concepts and the realization density", Atomization and Sprays, vol.5, pp. 435-455

Esfarjani S.A., Dolatabadi A. A. (2009). "3D simulation of two-phase flow in an effervescent atomizer for suspension plasma spray", Surface \& Coatings Technology, Vol. 203(15). Pp. 2074-280

Faeth G. M., Hsiang I. P., Wu P. K. (1995). "Structure and breakup properties of sprays", Int. J. Multiphase Flow, vol. 21, pp. 99-127

Ferreira G., Garciia J.A., Barreras F., Lozano A., Lincheta E. (2009). "Design optimization of twin-fluid atomizers with an internal mixing chamber for heavy fuel oils", Fuel Processing Technology, Vol 90(2), pp. 270-8.

Ferreira M. E., Teixeira J. C. F., Bates, C. J., Bowen, P. J. (2001). "Detailed Investigation of the Influence of Fluid Viscosity on the Performance Characteristics of Plain-Orifice Effervescent Atomizers", Atomization and Sprays, vol. 11 (2)

Ferreira G., García J. A., Barreras F., Lozano A., Linchetta E. (2009). "Design optimization of twin-fluid atomizers with an internal mixing chamber for heavy fuel oils", Fuel Processing Technology, vol. 90, pp. $270-278$

Gadgil H.P., Raghunandan B.N. (2011). "Some features of spray breakup in effervescent atomizers", Experiments in Fluids, Vol. 50(2), pp. 329-38.

Golan L.P., Stenning A.H. (1969). "Two-Phase Vertical Flow Maps", Proc. Inst. Mech. Eng., vol. 184 (3C), pp. $110-116$

Gottlieb N., Schwartzbach C. (2004), "Development of an internal mixing two-fluid nozzle by systematic variation of internal parts", ILASS Europe, Nottingham, UK 
Hanson A. R., Domich E. G., Adams H. S. (1963). "Shock-tube investigation of the breakup of drops by air blasts", Phys. Fluids, vol. 6, pp.1070-1080

Hewitt G. F., Roberts D. N. (1969). "Studies of Two-Phase Flow Patterns by Simultaneous Flash and XRay Photography", AERE-M2159

Hinze J. O. (1955). "Fundamentals of the hydrodynamic mechanism of splitting in dispersion processes", AlChE Jl, vol. 1, pp. 289-295

Hong M. Fleck B., Nobes D. S. (2014). "Unsteadiness of the internal flow in an effervescent atomizer nozzle", Experiments in Fluids, vol. 55, DOI 10.1007/s00348-014-1855-9

Hsiang J., Faeth L. P. (1992). "Near-limit drop deformation and secondary breakup", Int. J. Multiphase Flow, vol. 18, pp. 635-652

Huang X., Wang X.S., Liao G.X. (2011). "Characterization of an effervescent atomization water mist nozzle and its fire suppression tests", Proceedings of the Combustion Institute, Vol. 33, pp. 2573-9

Chawla J.M. (1985). "Atomization of Liquids Employing the Low Sonic Velocity in Liquid/Gas Mixtures", Proceedings of the Third ICLASS-85, pp. LP/1A/5/1-LP/A/5/7.

Chin J. S. (1995). "Effervescent Atomization and Internal Mixing Air Assisted Atomization", Int. J. Turbo Jet Engines, vol. 12, pp.119-127

Chung I. P., Strupp Ch., Karan J. (2000). "New Fuel Oil Atomizer For Improved Combustion Performance and Reduced Emissions", 6th European conference on industrial furnace and boilers, Lisbon

Jagannathan T.K., Nagarajan R., Ramamurthi K. (2011). "Effect of ultrasound on bubble breakup within the mixing chamber of an effervescent atomizer", Chemical Engineering and Processing, Vol. 50(3), pp. 305-15.

Jedelský J., Jícha M. (2012). "Spatially and temporally resolved distributions of liquid in an effervescent spray", Atomization and Sprays, vol. 22 (7), pp. 603-626 
Jedelsky J., Jicha M., Slama J., Otahal J. (2009). "Development of an Effervescent Atomizer for Industrial Burners", Energy \& Fuels, Vol. 23, pp. 6121-6130

Jolodar A.J., Akbarnejad M.M., Taghizadeh M., Marvast M.A. (2005). "Laser-based flow measurement in performance assessment of FCC atomizer", Chemical Engineering Journal, vol. 108(1-2), pp. 109-115.

Karnawat J., Kushari A. (2006). "Controlled atomization using a twin-fluid swirl atomizer", Experiments in Fluids, Vol. 41(4), pp. 649-663

Kermes V., Belohradsky P., Oral J., Stehlik P. "Testing of gas and liquid fuel burners for power and process industries", Energy, Vol. 33(10), pp. 1551-1561

Krzeczkowski S. A. (1980). "Measurement of liquid droplet disintegration mechanisms", Int. J. Multiphase Flow, vol. 6, pp. 227-239

Lal S., Kushari A., Gupta M., Kapoor J.C., Maji S. (2010). "Experimental study of an air assisted mist generator", Experimental Thermal and Fluid Science, Vol. 34(8), pp. 1029-1035

Lefebvre A.H. (1988). "A novel method of atomization with potential gas turbine application", Indian Defence Sci. J., vol. 38

Lefebvre A.H., Wang X.F., Martin C.A. (1988). "Spray characteristics of aerated-liquid pressure atomizers", Journal of Propulsion and Power. Vol. 4, pp. 293-298

Lincheta E., Barroso J., Suárez J., Barreras F., Lozano A. (2002). "Performance of Internal Mixing Air-Assisted Nozzles for Heavy Fuel Oil Burners", ILASS-Europe, Zaragoza

Liu M., Duan Y.F., Zhang T.N., Xu Y.Q. (2011). "Evaluation of unsteadiness in effervescent sprays by analysis of droplet arrival statistics - The influence of fluids properties and atomizer internal design", Experimental Thermal and Fluid Science, Vol. 35(1), pp. 1908.

Loebker D., Empie H.J. (1997). "High mass flow-rate effervescent spraying of high viscosity Newtonian liquid", 10th Annual Conference on Liquid Atomization and Spray Systems. Ottawa, pp. 253-257 
Loebker D., Empie H.J., Tappi. (1998), “Effervescent spraying: A new approach to spraying high solids black liquor", TAPPI International Engineering Conference, Miami, pp. 157-167

Loparev V. P. (1975). "Experimental investigation of the atomization of drops of liquid under conditions of a gradual rise of the external forces", Izv. Akad. Nauk SSSR. Mekh. Zh. Gaza, vol 3, pp.174-178

Lorcher M., Schmidt F., Mewes D. (2003). "Flow field and phase distribution inside effervescent atomizers", 9th ICLASS 2003, pp.12-9

Luong J. T., Sojka P. E. (1999). "Unsteadiness in effervescent sprays", Atomization and sprays, vol. 9, pp. 87-109

Mujumdar A.S., Huang L.X., Chen X.D. (2010). "An overview of the recent advances in spraydrying", Dairy Science \& Technology, Vol. 90(2-3), pp. 211-24

Mullinger P.J., Chigier N.A. (1974). "The design and performance of internal mixing multijet twin-fluid atomizers", Journal of the Institute of Fuel, vol. 47, pp. 251-261

Ochowiak M. (2013). "The experimental study on the viscosity effect on the discharge coefficient for effervescent atomizers", Experimental Thermal and Fluid Science, Vol. 50, pp 187192, ISSN 0894-1777

Panao M.R.O., Moreira A.L.N. (2005). "Thermo- and fluid dynamics characterization of spray cooling with pulsed sprays", Experimental Thermal and Fluid Science, Vol. 30(2), pp. 7996

Pougatch K., Salcudean M., McMillan J. (2014). "Influence of mixture non-uniformity on the performance of an effervescent nozzle", Fuel, Vol.116, pp. 601-607

Qian L.J., Lin J.Z., Xiong H.B. (2011). "Modeling of non-Newtonian suspension plasma spraying in an inductively coupled plasma torch", International Journal of Thermal Sciences. Vol. 50(8), pp. 1417-27

Risberg M., Marklund M. (2009). "Visualizations of gas-assisted atomization of black liquor and syrup/water mixtures at elevated ambient pressures", Atomization and Sprays, Vol. 19(10), pp. 957-67 
Santangelo P.J., Sojka P.E. (1995). "A holographic investigation of the near-nozzle structure of an effervescent atomizer-produced spray", Atomization and Sprays, vol. 5(2), pp. 137-55

Sher, E., Koren, M., Katoshewski, D., Kholmer, V. (2000). "Energy Consideration and Experimental Study of Effervescent Atomizers", Proc. ILASS-Europe 2000. Paper II.7.

Schicht H. H. (1969). "Flow patterns for an adiabatic two-phase flow of water and air within a horizontal tube", Verfahrenstechnik, vol. 3(4), pp.153-161

Song S.H., Lee S.Y. (1996). "Study of atomization mechanism of gas/liquid mixtures flowing through Y-jet atomizers", Atomization and sprays, vol. 6, pp. 193-209

Sovani S.D., Sojka P.E, Lefebvre A.H (2001): "Effervescent atomization", Progress in Energy and Combustion Science, vol. 27(4), pp. 483-521

Schröder, J., Kleinhans, A., Serfert, Y., Drusch, S., Schwarz, K., Schuchmann, H. P., \& Gaukel, V. (2012). "Viscosity ratio: A key factor for control of oil drop size distribution in effervescent atomization of oil-in-water emulsions". Journal Of Food Engineering, Vol. 111, pp. 265-271.

Schröder, J., Kraus, S., Rocha, B. B., Gaukel, V., \& Schuchmann, H. P. (2011). "Characterization of gelatinized corn starch suspensions and resulting drop size distributions after effervescent atomization". Journal Of Food Engineering, Vol. 105, pp. 656-662.

Stähle P., Gaukel V., Schuchmann H.P. (2013). "Influence of mixing chamber length and liquid viscosity on the effervescent atomization of maltodextrin solutions", ILASS - Europe, Chania, Greece

Stähle, P., Gaukel, V., \& Schuchmann, H. P. (2014). "Investigation on the Applicability of the Effervescent Atomizer in Spray Drying of Foods: Influence of Liquid Viscosity on Nozzle Internal Two-Phase Flow and Spray Characteristics". Journal of Food Process Engineering, (Early View)

Tamaki N., Shimizu M., Hiroyasu H. (2004). "Atomization of High viscous Liquid Jet by Internal Mixing Twin-Fluid Atomizer", ILASS Europe, pp. 412-417 
Wade R.A., Weerts J.M., Sojka P.E., Gore J.P., Eckerle W.A. (1999). „Effervescent atomization at injection pressures in the MPa range", Atomization and Sprays. Vol. 9(6), pp. 651-667.

Weisman J., Kang S.Y. (1981). "Flow pattern transitions in vertical and upwardly inclined lines", Int. J. Multiphase Flow, vol. 7(27)

Whitlow J. D., Lefebvre, A. H. (1993). "Effervescent Atomizer Operation and Spray Characteristics", Atomization and Sprays, Vol. 3, pp. 137-155

Xiuyuan M., Yufeng D., Meng L. (2013). "Atomization of petroleum-coke sludge slurry using effervescent atomizer", Experimental Thermal and Fluid Science, Vol.46, pp 131-138, ISSN 0894-1777

Zhou Y., Zhang M., Yu J., Zhu X., Peng J. (2010). "Experimental investigation and model improvement on the atomization performance of single-hole $\mathrm{Y}$-jet nozzle with high liquid flow rate", Powder Technology Vol. 199, pp. 248-255 


\section{LIST OF FIGURES}

Figure 1. Arrangement of the measurement and visualization systems

Figure 2. Simplified schematic of the experimental rig

Figure 3. Schematics of the investigated atomizers: a) Y-jet, b) OIG, c) OIL, d) CFT

Figure 4. Image pre-processing

Figure 5. Particle (ligament) tracking

Figure 6. Liquid breakup regimes

Figure 7. Near-nozzle spray pattern for $\mu=308 \mathrm{mPa} \cdot \mathrm{s}$

Figure 8. Near-nozzle spray pattern for $\mu=143 \mathrm{mPa} \cdot \mathrm{s}$

Figure 9. Near-nozzle spray pattern for $\mu=60 \mathrm{mPa} \cdot \mathrm{s}$

Figure 10. Comparison of the gas-to-liquid momentum ratio for the OIL and Y-jet atomizers

Figure 11. Estimated internal flow of the $\mathrm{Y}$-jet atomizer

Figure 12. Two-phase flow patterns

Figure 13. The estimated two-phase flow for the OIL atomizer

Figure 14. Measured Sauter mean diameter at $100 \mathrm{~mm}$ downstream of the discharge orifice, measured only for regimes with well-developed sprays 


\section{LIST OF TABLES}

Table 1. Physical properties of the water-maltodextrin solutions at room temperature

Table 2. The important geometrical parameters of the atomizers

Table 3. Measured liquid mass flow rates in $[\mathrm{kg} / \mathrm{hod}]$ for all atomizers and working regimes

Table 4. Assessment of spray cone stability

Table 5. Spray cone stability

Table 6. Internal flow patterns of the OIG and OIL atomizers, estimated using the baker's map

Table 7. Calculated standard deviations of SMD $[\mu \mathrm{m}]$ 